\title{
Comemorando 15 anos de Avanço na Área de Avaliação Psicológica
}

\section{Celebrating 15 years of Advancement in the Area of Psychological Assessment}

\author{
Celebrando 15 años de Avance en el Área de Evaluación Psicológica
}

\author{
Acácia Angeli dos Santos ${ }^{1}$ \\ ${ }^{1}$ Universidade São Francisco, SP, Brasil.
}

Um dos números especiais do ano de 2018 é dedicado à comemoração dos 15 anos de existência do Sistema de Avaliação de Testes Psicológicos (Satepsi) do Conselho Federal de Psicologia (CFP). O fato é muito importante para a área e, como uma das muitas formas de registrar este acontecimento, foi organizado este número especial com a participação de autores especialmente convidados. Eles são responsáveis por ganhos expressivos alcançados na área e a maioria esteve diretamente envolvida em uma das gestões da Comissão Consultiva em Avaliação Psicológica (CCAP).

Vale ressaltar que o Satepsi é um dos poucos modelos de avaliação de testes psicológicos no cenário mundial. E, como não poderia deixar de ser, trouxe resultados significativos para a área de avaliação psicológica brasileira, à medida que impôs um sistema operacional, que permite a reunião de dados; uma regulamentação específica; e uma comissão de especialistas, que fornece elementos técnicos e científicos ao sistema.

No primeiro artigo deste número especial, intitulado "Impacto dos 15 Anos do Satepsi na Avaliação Psicológica Brasileira”, Caroline Tozzi Reppold e Ana Paula Porto Noronha focalizam os aspectos mais relevantes ocorridos desde a instalação do Satepsi. As autoras referem as principais ações do sistema e enfatizam o seu papel para a ampliação da conscientização das psicólogas e dos psicólogos sobre o uso dos testes psicológicos.

As inovações da Resolução no 09/2018, publicada pelo CFP em 25 de abril de 2018, constam no artigo “O que muda com a Resolução CFP no 09/2018?", de autoria de Fabian Javier Marín Rueda e Daniela Sacramento Zanini, ambos conselheiros do XVIII Plenário do CFP e responsáveis pela área de avaliação psicológica. Além de relatarem o processo de construção da resolução e os avanços nela contidos, os autores apresentam uma síntese das ações realizadas até o presente momento pela CCAP.

Josemberg Moura de Andrade e Felipe Valentini são os responsáveis pelo artigo "Diretrizes para a Construção de Testes Psicológicos: a Resolução CFP nº 009/2018 em Destaque”. Eles abordam os principais parâmetros psicométricos, dando destaque para as modificações apresentadas pela Resolução no 09/2018, bem como para suas implicações. Ao final, afirmam que os avanços técnicos e científicos da área poderão impulsionar os desenvolvedores de testes a buscarem o aprimoramento deles e do processo de avaliação psicológica.

Os aspectos históricos que fundamentaram a decisão do CFP de criar um sistema de análise dos instrumentos são abordados por Lucila Moraes Cardoso e José Humberto da Silva-Filho no artigo "Satepsi e a Qualidade Técnica dos Testes Psicológicos no Brasil". Os autores discutem a evolução das características dos testes psicológicos disponíveis para uso no Brasil e asseguram que o sistema favorece sua qualificação e os torna acessíveis aos psicólogos.

Cristiane Faiad e Iraí Cristina Boccato Alves, no artigo "Contribuições do Satepsi para Avaliações Psicológicas Compulsórias (Trânsito, Porte de Arma e Concursos Públicos)”, apresentam um panorama geral dessas avaliações. As autoras discorrem sobre o papel do Satepsi para 
a melhoria dessas práticas, mas alertam que muitos investimentos no campo da pesquisa ainda serão necessários para subsidiar a atuação dos profissionais em cada uma desses contextos.

Proposições importantes sobre o processo de avaliação psicológica de indivíduos com deficiência intelectual são trazidas no artigo "Avaliação Psicológica na Educação Especial na Perspectiva da Educação Inclusiva" de autoria de Alexandra Ayach Anache. Trata-se de um ensaio acadêmico que discute os processos avaliativos na perspectiva histórico-cultural, no qual a autora salienta a importância da avaliação-intervenção, mostrando a relevância de se valorizar o processo de desenvolvimento do indivíduo para construir explicações sobre a sua dinâmica psicológica.

"Formação em Avaliação Psicológica: Situação, Desafios e Diretrizes" é o título do artigo de Valdiney Veloso Gouveia, que descreve como tem ocorrido no Brasil a formação na área, identificando desafios, avanços e diretrizes. O autor, com larga trajetória na área e responsável pela formação de muitos psicólogos no nordeste brasileiro, considera que é necessário diferenciar os níveis de formação e sugere que seja dada especial atenção ao ensino dos documentos que regulamentam a profissão.

Um enquadramento amplo da avaliação psicológica dentre as atividades profissionais da psicóloga e do psicólogo, é realizado por Ricardo Primi no artigo "Avaliação Psicológica no Século XXI: de Onde Viemos e para Onde Vamos". O texto chama a atenção para as mudanças produzidas por eventos científicos e históricos nos últimos cinco anos e aponta para um novo papel da avaliação psicológica no mundo.

O artigo "Modelo de Testagem Universal Aplicado à Área da Avaliação Psicológica” foi escrito por Carlos Henrique Sancineto da Silva Nunes e Cassandra Melo Oliveira, mostrando seu principal desdobramento para o desenvolvimento de instrumentos em Psicologia - a Testagem Universal (TU). Os autores trazem um roteiro para elaboração de testes segundo estes princípios, o que reduz a necessidade de adaptações posteriores à publicação. O texto é finalizado com a apresentação de uma proposta de um Modelo Integrativo de Testagem Universal.

Considerando a relevância histórica do desenvolvimento da Psicologia como ciência e profissão, José Maurício Haas Bueno e Evandro Morais Peixoto, no artigo "Avaliação Psicológica no Brasil e no Mundo", fazem um paralelo entre o desenvolvimento da área de avaliação psicológica ao longo dos tempos. Contribuindo para o entendimento dos caminhos percorridos e de direções futuras, os autores levam em conta os aspectos éticos e técnicos, bem como ações político-administrativas relevantes nessa trajetória.

Anna Elisa de Villemor-Amaral e Ana Cristina Resende são as autoras do artigo "Novo Modelo de Avaliação Psicológica no Brasil”, no qual são discutidos problemas mais comuns nos processos de avaliação psicológica no modelo tradicional. Ao apresentarem uma proposta em expansão, a Avaliação Terapêutica (AT), referem seu planejamento cuidadoso, característica colaborativa e a intervenção que se inicia durante o processo avaliativo. As autoras finalizam o texto trazendo contextos possíveis de aplicação da AT.

"Ética na Avaliação Psicológica: Velhas Questões, Novas Reflexões" é desenvolvido no artigo de autoria de Monalisa Muniz, que traz reflexões sobre as questões nele envolvidas. Para a autora, os documentos normativos da profissão no Brasil reafirmam o caráter dinâmico, transformador, cultural e benéfico de uma Psicologia e avaliação psicológica pautadas na ética. Ao discutir a formação em avaliação psicológica, ela salienta a necessidade de uma formação ética permanente, que vá além da formação estritamente profissional.

Uma das discussões prementes nos últimos anos é o uso de testes psicológicos por profissionais não psicólogos. Ela é abordada por Denise Ruschel Bandeira no artigo "A Controvérsia do Uso dos Testes Psicológicos por Psicólogos e Não Psicólogos”. Considerando as características da formação em Psicologia, bem como o processo de avaliação de testes no Brasil, a autora apresenta alternativas e defende a ideia de que o uso de instrumentos seja garantido a quem tenha formação e qualificação, não o restringindo apenas à posse do registro profissional no sistema conselho de Psicologia.

O artigo "Direitos Humanos e Avaliação Psicológica: Indissociabilidade do compromisso ético-político profissional", de autoria de Pedro Paulo Bicalho e Erick Vieira, foi escrito com base no entendimento de que o exercício dos direitos humanos no processo de avaliação psicológica deve estar presente não apenas na construção de seus instrumentos, mas também em sua aplicação. Os autores defendem que a postura ético-política de quem executa a avaliação leve sempre em conta a subjetividade dos avaliandos, considerando o processo sócio-histórico de sua constituição. 
Este número especial estaria incompleto se não houvesse espaço para que fossem apresentadas as homenagens a autores que dedicaram grande parte de suas vidas à área de avaliação psicológica, responsáveis também pela formação de muitas pessoas. Indicados por ex-alunos e por colegas, muitos dos homenageados continuam a trabalhar ativamente na área. Dentre eles estão Claudio Hutz, sobre quem Claudia Giacomoni escreveu o texto-homenagem, repartindo conosco o conhecimento de quem tem o homenageado como orientador e colega. Regina Sonia Gattas Fernandes do Nascimento, que também já integrou a Comissão Consultiva, escreveu o texto-homenagem a Latife Yazigi, de quem tem sido parceira de pesquisa e amiga nos muitos anos de convivência. Também Luiz Pasquali, criador de um dos primeiros laboratórios da área na Universidade de Brasília, é homenageado pela sua última orientanda de doutorado, Manuela Ramos Caldas Lins, que partilha aqui dados de seu convívio com este notável pesquisador. Por fim, o texto-homenagem a Solange Wechsler, de autoria de Tatiana de Cassia Nakano, retrata a trajetória da pesquisadora, com quem ela tem compartilhado a realização de muitos instrumentos na área de criatividade, à qual ambas têm se dedicado.

Um outro bloco de homenagens é dedicado a autores que contribuíram expressivamente para a área de avaliação psicológica e deixaram legados importantes, continuando a fazer história, sem estar mais fisicamente presente. Neste grupo estão André Jacquemin, cujo texto-homenagem foi escrito por Sonia Regina Pasian e Erika Tiemi Kato Okino, duas psicólogas que trilharam com ele os caminhos da avaliação psicológica na Faculdade de Filosofia da Universidade de São Paulo em Ribeirão Preto, durante parte consi- derável de seu percurso e repartem conosco experiências destes tempos. Blanca Werlang, companheira de CCAP durante vários anos, é homenageada por um quarteto de psicólogas, Clarissa Marceli Trentini, Samantha Dubugras Sá, Margareth da Silva Oliveira e Irani Iracema de Lima Argimon, que com ela conviveram intensamente na cidade de Porto Alegre, tanto na Pontifícia Universidade Católica do Rio Grande do Sul (PUC-RS) como na Universidade Federal do Rio Grande do Sul (UFRGS) e tiveram com ela laços de trabalho e grande amizade.

Entendemos que os textos publicados nesta edição especial oferecem uma oportunidade singular de contato, não só com as recentes alterações da regulamentação da área de avaliação psicológica, mas também com reflexões sobre os desafios que estão sempre presentes. Ademais, trazem mais próximo dos leitores histórias de personagem de grande importância para a Psicologia brasileira.

Ao finalizar, julgamos indispensável registrar o nosso agradecimento ao XVII Plenário do CFP que aprovou a presente publicação. Também, expressamos nosso reconhecimento à generosidade do Conselho Editorial da Revista Psicologia: Ciência e Profissão, que nos abriu este importante espaço de diálogo com as psicólogas, os psicólogos e com a sociedade.

\section{Acácia Angeli dos Santos}

Editora convidada. Universidade São Francisco - SP. Brasil.

E-mail: acacia.santos@usf.edu.br

Como citar: Santos, A.A.A. (2018). Comemorando 15 anos de Avanço na Área de Avaliação Psicológica.Psicologia: Ciência e Profissão, 38(n.spe), 1-3. https://doi.org/10.1590/1982-3703000102018

How to cite: Santos, A.A.A. (2018). Celebrating 15 years of Advancement in the Area of Psychological Assessment. Psicologia: Ciência e Profissão, 38(n.spe), 1-3. https://doi.org/10.1590/1982-3703000102018

Cómo citar: Santos, A.A.A. (2018). Celebrando 15 años de Avance en el Área de Evaluación Psicológica. Psicologia: Ciência e Profissão, 38(n.spe), 1-3. https://doi.org/10.1590/1982-3703000102018 